\title{
Downscaling SMAP and SMOS soil moisture retrievals over the Goulburn River Catchment, Australia
}

\author{
I.P. Senanayake ${ }^{\text {a }}, \underline{\text { I.Y. Yeo }}{ }^{\text {a }}$, N. Tangdamrongsub ${ }^{\text {a }}$, G.R. Willgoose ${ }^{\text {a }}$, G.R. Hancock ${ }^{\text {, }}$ T. Wells ${ }^{\text {a }}$, \\ B. Fang ${ }^{\mathrm{c}}$ and V. Lakshmic \\ a School of Engineering, Faculty of Engineering and Built Environment, The University of Newcastle, \\ Callaghan, NSW 2308, Australia. \\ ${ }^{b}$ School of Environmental and Life Sciences, Faculty of Science, The University of Newcastle, Callaghan, \\ NSW 2308, Australia. \\ ${ }^{c}$ School of Earth Ocean and Environment, University of South Carolina, Columbia, \\ SC 29223, United States. \\ Email: Indishe.Senanayake@uon.edu.au
}

\begin{abstract}
Soil moisture is an important variable in a number of environmental processes - specifically the hydrological cycle, in the water-limited environments. Therefore, soil moisture data is important as an input variable in hydrologic, climatic modelling and agricultural applications. Many of these applications require high-resolution soil moisture data. However, most of the available soil moisture measurements are rarely available at high resolution, therefore unable to capture the spatial heterogeneity of soil moisture with required accuracy levels. Thus, upscaling or downscaling of soil moisture observations to higher spatial resolution is an essential requirement for these multidisciplinary applications. A long-term high-resolution soil moisture dataset is useful for planning and decision making in agriculture, climatology and hydrology. Developing a historic soil moisture dataset at high spatial resolution over a long period requires the use of different satellite soil moisture products. However, the use of different satellite products results in incompatibilities among each other due to discrepancies in overpass times, the wavelengths used, retrieval algorithms, orbital parameters and sensor errors. Therefore, validation and comparison of soil moisture retrievals from different satellite sensors and their downscaled products is important in evaluating the consistency of a long-term time series dataset of high-resolution soil moisture.
\end{abstract}

This study focusses on a downscaling algorithm based on the thermal inertia theory at two sub-catchments of the Goulburn River in south-eastern Australia, Krui and Merriwa River catchments. The goal is to downscale the radiometric soil moisture retrievals of Soil Moisture Active Passive (SMAP) and Soil Moisture and Ocean Salinity (SMOS) missions along with validation using established in-situ observation networks.

A linear regression model was developed between the daily surface temperature difference and daily mean soil moisture values from the in-situ observations of the Scaling and Assimilation of Soil Moisture and Streamflow (SASMAS) project. This relationship is modulated by the vegetation cover and soil attributes. The MODerateresolution Imaging Spectroradiometer (MODIS) derived land surface temperature difference values were fitted into the lookup algorithms to estimate surface soil moisture at fine spatial resolution at $1 \mathrm{~km}$. The coarseresolution SMAP $(36 \mathrm{~km})$ and SMOS $(25 \mathrm{~km})$ radiometric soil moisture products were downscaled to $1 \mathrm{~km}$.

The coarse-resolution SMAP and SMOS soil moisture datasets were compared with each other, and then against the SASMAS in-situ measurements. SMAP $36 \mathrm{~km}$ datasets show a reasonable agreement with the insitu data with RMSEs of 0.07 and $0.05 \mathrm{~cm}^{3} / \mathrm{cm}^{3}$ over two SMAP pixels. However, SMOS $25 \mathrm{~km}$ soil moisture products show a general underestimation as compared to SMAP and SASMAS datasets. Therefore, the SMOS data were calibrated with SMAP data. Subsequently, the SMAP, SMOS and adjusted SMOS datasets over the Krui and Merriwa River catchments for the year 2015 were downscaled and compared.

The results show that the accuracy of the downscaled soil moisture datasets are highly influenced by the accuracy of the coarse-resolution satellite soil moisture products. The downscaled data were compared with in-situ data of five SASMAS monitoring stations. The downscaled SMAP, SMOS and adjusted SMOS datasets respectively showed average RMSEs of 0.10 (standard deviation, $\sigma=0.05), 0.19(\sigma=0.07)$ and $0.13(\sigma=0.02)$ $\mathrm{cm}^{3} / \mathrm{cm}^{3}$ with the SASMAS in-situ measurements. The three downscaled datasets of SMAP, SMOS and adjusted SMOS show consistent soil moisture pattern over the study catchments. The downscaled adjusted SMOS data displayed a better agreement with downscaled SMAP soil moisture data compared to the nonadjusted SMOS data.

Key words: $\quad$ Downscaling, SMAP, SMOS, soil moisture, thermal inertia 
Senanayake et al., Downscaling SMAP and SMOS soil moisture retrievals over the Goulburn River Catchment, Australia

\section{INTRODUCTION}

Soil moisture is a key variable in a number of environmental processes in arid and semi-arid environments. Therefore, soil moisture data are required for hydrological modelling, climatic modelling and agricultural applications (Western et al., 2002). The spatial and temporal variability of soil moisture is determined by the spatial heterogeneity of the land surface that includes land use/land cover, topography, and soil texture as well as meteorological factors such as rainfall, wind speed, radiation and humidity (Western et al., 2002).

The available remotely sensed soil moisture products are unable to capture the catchment and field-scale soil moisture variability as required by many applications due to their coarser resolutions (Fang and Lakshmi, 2014). Therefore, it is necessary to downscale satellite soil moisture data into finer spatial resolutions. Developing a long-term soil moisture dataset often requires soil moisture products from more than one satellite. However, different satellite soil moisture products show inconsistencies due to the disparities in spatial resolution, wavelength, retrieval algorithms, overpass times and penetration depths. Therefore, validation of satellite soil moisture retrievals and their downscaled products are important in order to maintain the consistency of a long-term high-resolution dataset of soil moisture.

The main objectives of this study is to use the thermal inertia relationship between diurnal soil temperature difference $(\Delta T)$ and the daily mean soil moisture $(\theta \mu)$ to downscale the SMAP and SMOS L-band radiometric soil moisture retrievals over the Krui and Merriwa River catchments, two sub-catchments of the Goulburn River, in the Upper Hunter region of New South Wales, Australia and to compare and validate the downscaled soil moisture products of SMAP and SMOS. The results of this study will provide insights in developing a long-term time series of high-resolution soil moisture data during the period of SMOS and SMAP data availability.

\section{THEORY AND BACKGROUND OF THE RESEARCH}

The downscaling theory presented here is based on the thermal inertia relationship between $\Delta T$ and $\theta \mu$. $\Delta T$ can be expressed as $T_{P M}-T_{A M}$, where $T_{P M}$ and $T_{A M}$ are soil surface temperatures in the afternoon and the morning respectively. Thermal inertia $(D)$ is a property that characterizes the degree of resistance of a body to the change of its surrounding temperature. The diurnal temperature difference of the soil $\left(\Delta T_{s}\right)$ is inversely proportional to the diurnal thermal inertia of the soil $\left(D_{s}\right)$ (Eq. 1) (Engman, 1991).

$$
\Delta T_{s}=f\left(\frac{1}{D_{s}}\right)
$$

Thermal inertia is a function of material's density $(\rho)$, thermal conductivity $(K)$ and specific heat capacity $(c)$ (Price, 1977).

$$
D=\sqrt{\rho . K . c}
$$

The thermal inertia of water is higher than of the dry soils, hence wet soil exhibits lower $\Delta T_{s}$ change compared to the dry soils. Therefore, when the soil moisture content is increasing, $D_{s}$ of soil increases proportionally. This phenomenon is used in this study to develop regression relationships between the $\Delta T$ and $\theta \mu$, which is consequently used to estimate $\theta \mu$ for a given $\Delta T$.

Fang and Lakshmi (2014) and Fang et al. (2013) have employed this concept to downscale AMSR-E and SMOS soil moisture products over the Little Washita watershed in Oklahoma, United States by developing monthly $\Delta T-\theta \mu$ relationships modulated by the vegetation density by using the North American Land Data Assimilation System (NLDAS) datasets. Senanayake et al. (2017) has tested this methodology to downscale SMAP radiometric soil moisture products over the Krui and Merriwa River catchments in NSW, Australia. In that study, the hourly in-situ soil moisture and temperature data acquired in the year 2015 from the SASMAS project has been used to develop the regression model. The data from the $0-30 \mathrm{~cm}$ soil profile was employed in that work due to the limited availability of the SASMAS in-situ data at 0-5 cm soil profile in the year 2015 . However, SMAP and SMOS satellites observe soil moisture at approximately the top $5 \mathrm{~cm}$ of soil. This mismatch between the soil profiles observed in satellite and in-situ measurements caused uncertainties in the results. The soil clay content has also been included as a modulating factor in that study by considering the effect of soil texture to the $\Delta T-\theta \mu$ relationship (Engman, 1991).

The work presented here is an extension of Senanayake et al. (2017) by employing the SASMAS soil moisture and soil temperature data of the entire time period of data availability, i.e. from 2003 to 2015 , to develop the 
Senanayake et al., Downscaling SMAP and SMOS soil moisture retrievals over the Goulburn River Catchment, Australia

regression model. This facilitates the use of datasets at $0-5 \mathrm{~cm}$ soil profile, which is more compatible with the L-band satellite soil moisture retrievals. Furthermore, the use of a long-term dataset generalizes the regression model across the temporal domain and captures a higher range of seasonal and vegetation conditions.

\section{GOULBURN RIVER CATCHMENT AND THE SAMAS IN-SITU DATASET}

The study area, Goulburn River catchment, is located in New South Wales, Australia about 200 km northwest to Newcastle city extending from $31^{\circ} 46^{\prime} \mathrm{S}$ to $32^{\circ} 51^{\prime} \mathrm{S}$ and from $149^{\circ} 40^{\prime} \mathrm{E}$ to $150^{\circ} 36^{\prime} \mathrm{E}$. The Goulburn River flows generally from west to east with its tributaries flow from north to south. The catchment encompasses a temperate and semi-arid climate. Monthly mean maximum temperature of the catchment reaches $30^{\circ} \mathrm{C}$ in the summer and $14^{\circ} \mathrm{C}$ in the winter, while monthly mean minimum temperatures in the summer and winter reaches $16^{0} \mathrm{C}$ and $2^{0} \mathrm{C}$ respectively. The elevation of the catchment varies from approximately $100 \mathrm{~m}$ in the lower reaches to $1300 \mathrm{~m}$ in the northern and southern mountain ranges. The annual average precipitation is approximately $700 \mathrm{~mm}$, but varies across the catchment from $500 \mathrm{~mm}$ to $1100 \mathrm{~mm}$. The Goulburn River catchment can be divided into two distinct parts based on its geology, topography and land cover. The northern half of the catchment is mainly cleared for cropping and grazing while the southern half is covered by dense vegetation including a national park. The geology of the northern part consists of basalt-derived soils while the southern part consists of sandstones, conglomerate and shale (Rüdiger et al., 2007).

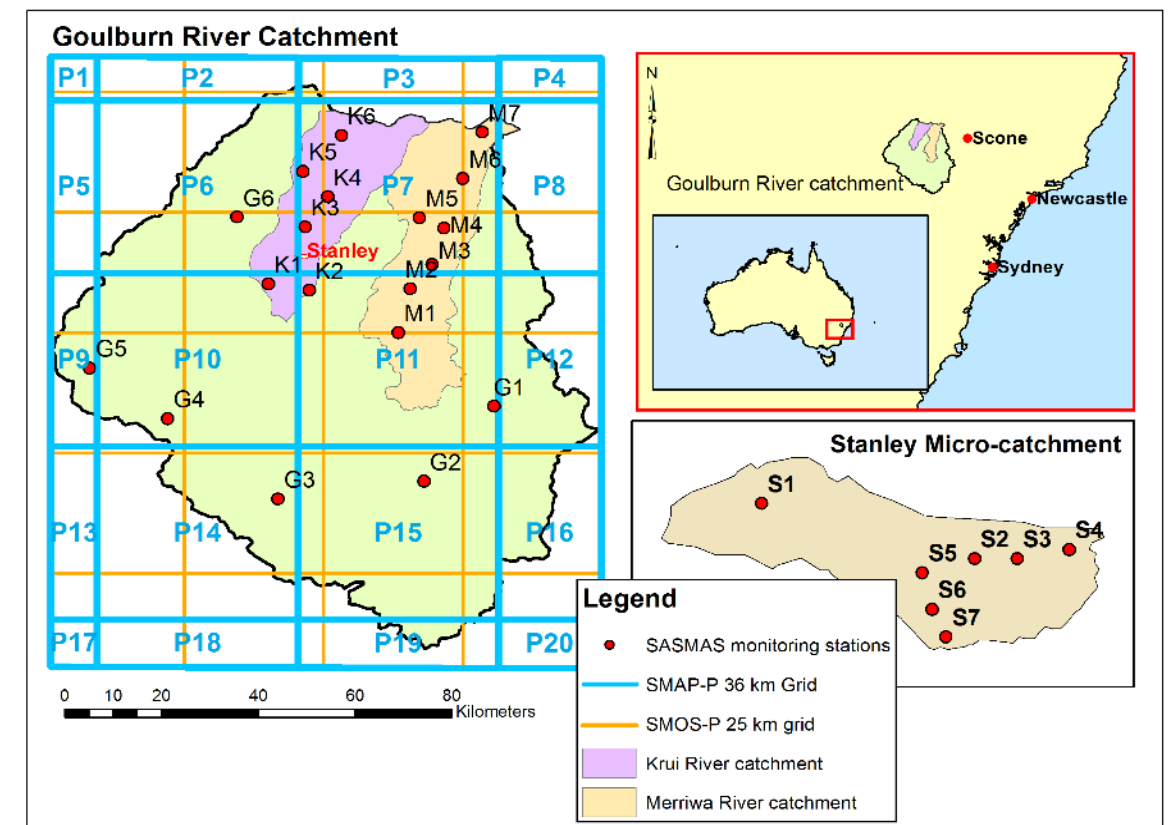

Figure 1. The Study area, Goulburn River catchment and SASMAS soil moisture monitoring stations. The SMAP $36 \mathrm{~km}$ pixels are numbered from $\mathrm{P}-1$ to $\mathrm{P}-20$.
The two focus subcatchments of this study, Krui and Merriwa River, are located in the northern part of the Goulburn River catchment. Krui and Merriwa River catchments have areas of $562 \mathrm{~km}^{2}$ and $651 \mathrm{~km}^{2}$ respectively and have a common catchment divide in the north-south direction in their northern reaches.

Twenty-six soil moisture monitoring stations have been established over the Goulburn River catchment under the SASMAS project in

2003 (Figure 1) (Rüdiger et al., 2007). The soil moisture is measured at soil depths of 0-30 cm, 30-60 cm and $60-90 \mathrm{~cm}$ by using Campbell Scientific CS616 water content reflectometers. Campbell Scientific T107 temperature sensors were installed vertically to measure the soil temperature of $0-30 \mathrm{~cm}$ soil profile. Stevens Water HydraProbes were installed at a later stage of the project to measure soil moisture and temperature at 0 $5 \mathrm{~cm}$ soil profile, which is more compatible with the L-band satellite soil moisture retrievals. Soil moisture and temperature are measured at each minute and logged at every 20-minute interval. Six monitoring stations have been established at the Krui River catchment and seven at Merriwa River catchment. A densely monitored Stanley micro-catchment is located in the southern half of the Krui River catchment with seven monitoring stations (Rüdiger et al., 2007). 
Senanayake et al., Downscaling SMAP and SMOS soil moisture retrievals over the Goulburn River Catchment, Australia

\section{METHODOLOGY}

\subsection{Comparison and validating of SMAP and SMOS soil moisture products}

The accuracy of the downscaled soil moisture products are highly dependent on the reliability of the coarseresolution satellite soil moisture products. A comparison among satellite soil moisture retrievals from different sensors and platforms is a requirement in developing a consistent time series of high-resolution soil moisture dataset. Therefore, SMAP Level 3 passive $(36 \mathrm{~km})$ and SMOS Level 3 passive $(25 \mathrm{~km})$ soil moisture datasets were compared across the Krui and Merriwa River catchments in 2015. The weighted average of SMOS data over four SMAP pixels, P-6, 7, 10 and 11 (Figure 1), were used in this comparison. The SMAP and SMOS datasets were obtained from the National Snow and Ice Data Center (NSIDC) and the Centre Aval de Traitement des Données SMOS (CATDS) respectively. The daily mean of SMOS ascending and descending data was used in this work as the SMOS derived $\theta \mu$. Furthermore, the SMAP and SMOS data across Krui and Merriwa River catchments were compared with the SASMAS in-situ measurements of 0-5 cm and 0-30 cm soil profiles based on the data availability.

The SMOS soil moisture dataset was linearly calibrated with the SMAP data across the study area, since SMOS soil moisture products showed a general underestimation. The calibrated SMOS data is termed 'adjusted SMOS data' onwards.

\subsection{Developing the regression model}

The thermal inertia relationship between $\Delta T$ and $\theta \mu$ is varying seasonally and modulated by the vegetation density and soil texture. Thermal conductivity of clay is higher than sandy soils due to the higher number of interparticle contacts in clay. This results in higher thermal inertia in clayey soils compared to sandy soils (Engman, 1991). Therefore, clay content was used as the soil parameter in this study based on its effect to the thermal inertia. Normalized difference vegetation index (NDVI) was employed in classifying the regression model based on the vegetation density.

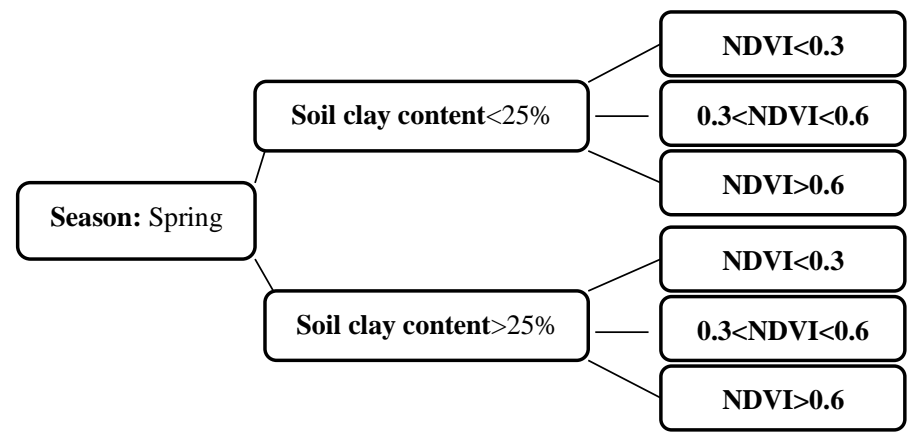

Figure 2. The regression model developed for the spring season including soil clay content and NDVI as modulating factors.

SASMAS hourly soil temperature and soil moisture data at $0-5 \mathrm{~cm}$ soil profile of the Krui River catchment monitoring stations from 2003 to 2015 were used in calculating $\Delta T$ and $\theta \mu$ values. The $\Delta T$ values were calculated based on the approximate MODIS-Aqua day and night overpass times, i.e. 13:30 and 01:30 hours local time (Eq. 3).

$$
\Delta T=T_{0130}-T_{1330}
$$

where $T_{0130}$ and $T_{1330}$ are the land surface temperature (LST) values of a particular point or pixel at 01:30 and 13:30 hours respectively.

A time series of 16-day NDVI estimates corresponding to the locations of Krui River catchment monitoring stations from 2003 to 2015 were extracted from the $1 \mathrm{~km}$ resolution MODIS MYD13A2 products. The extracted NDVI data was classified into three classes based on the vegetation density (Figure 2). The soil clay content at the Krui River catchment monitoring stations were obtained from SASMAS site characteristics and classified into two classes. In summary, the $\Delta T$ and $\theta \mu$ datasets were categorized into 24 classes based on the season, soil clay content and the NDVI. Figure 2 shows the classification of modulating factors for the spring season. Subsequently, linear regressions algorithms between $\Delta T$ and $\theta \mu$ were developed for each of these categories. Figure 3 demonstrates the regression fit for the spring season with clay content $<25 \%$ and NDVI $<0.3$. 
Senanayake et al., Downscaling SMAP and SMOS soil moisture retrievals over the Goulburn River Catchment, Australia

\subsection{Estimating soil moisture at high resolution based on the thermal inertia relationship}

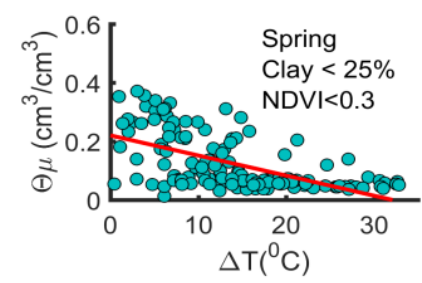

Figure 3. Linear regression fit developed for the spring season with soil clay content $<0.25$ and $\mathrm{NDVI}<0.3$.
The night-time and day-time $1 \mathrm{~km}$ LST data across the Krui and Merriwa River catchments over the year 2015 were extracted from the MODIS MYD11A1 products. The LST data were bias corrected by calibrating with the SASMAS in-situ soil temperature data. Afterwards, the $\Delta T$ values were calculated by computing the difference between the adjusted day-time and night-time LST values of each $1 \mathrm{~km}$ MODIS pixel (Eq. 3). The corresponding NDVI and soil clay content values for these $\Delta T$ values over the Krui and Merriwa River catchments in 2015 were extracted from MYD13A2 dataset and National Soil and Landscape Grid dataset (3" resolution) respectively. The $\Delta T$ values were then classified as per the regression model based on the season, clay content and NDVI classes. Thereafter, the $\theta \mu$ values were estimated by fitting the classified $\Delta T$ values into their respective look up curves according to the regression model (Figure 2).

\subsection{Downscaling SMAP and SMOS passive soil moisture retrievals}

The estimated $\theta \mu$ values were applied to a scaling equation (Eq. 4) to downscale SMAP, SMOS and adjusted SMOS datasets (modified from Fang and Lakshmi, 2014; Fang et al., 2013).

$$
\theta_{d s}(p)=\theta_{\text {est }}(p)+\left[\theta_{\text {sat }}-\frac{1}{N} \sum_{i=1}^{N} \theta_{\text {est }}\left(p_{i}\right)\right]
$$

where $\theta_{d s}(p)$ is the downscaled soil moisture at the $1 \mathrm{~km}$ pixel $p, \theta_{e s t}(p)$ is the soil moisture of the $1 \mathrm{~km}$ pixel $p$ estimated through the regression model, $\theta_{\text {sat }}$ is the soil moisture of the respective coarse-resolution satellite soil moisture product (for SMAP, $\theta_{\text {sat }}$ is the soil moisture of the respective $36 \mathrm{~km}$ SMAP pixel; for SMOS and adjusted SMOS, $\theta_{\text {sat }}$ is the average of ascending and descending soil moisture values of the respective $25 \mathrm{~km}$ SMOS pixel), $N$ is the number of $1 \mathrm{~km} p_{i}$ pixels within the respective coarse-resolution satellite pixel.

\subsection{Verification and comparison of datasets}

The validation of the downscaled datasets was carried out by using the SASMAS in-situ measurements. The only Krui and Merriwa River catchment monitoring stations where soil moisture and temperature data were available at 0-5 cm soil profile in 2015 were K3, M2 and M6. The in-situ measurements of these three stations were used along with the data from S-1 and S-3 stations of the Stanley micro-catchment for the validation process.

\section{RESULTS}

\subsection{Validation and comparison of satellite soil moisture products}

The validation of SMAP soil moisture data was carried out by using the SASMAS in-situ measurements acquired in 2015 . Two SMAP pixels, P-7 and P-11, were used for the validation process based on the data availability and distribution of the monitoring stations over the SMAP pixels. The RMSE values of the SMAP P-7 at $0-5 \mathrm{~cm}$ and $0-30 \mathrm{~cm}$ soil profiles are 0.070 and $0.074 \mathrm{~cm}^{3} / \mathrm{cm}^{3}$ respectively. At P-11, the SMAP's RMSE value of $0-30 \mathrm{~cm}$ soil profile is

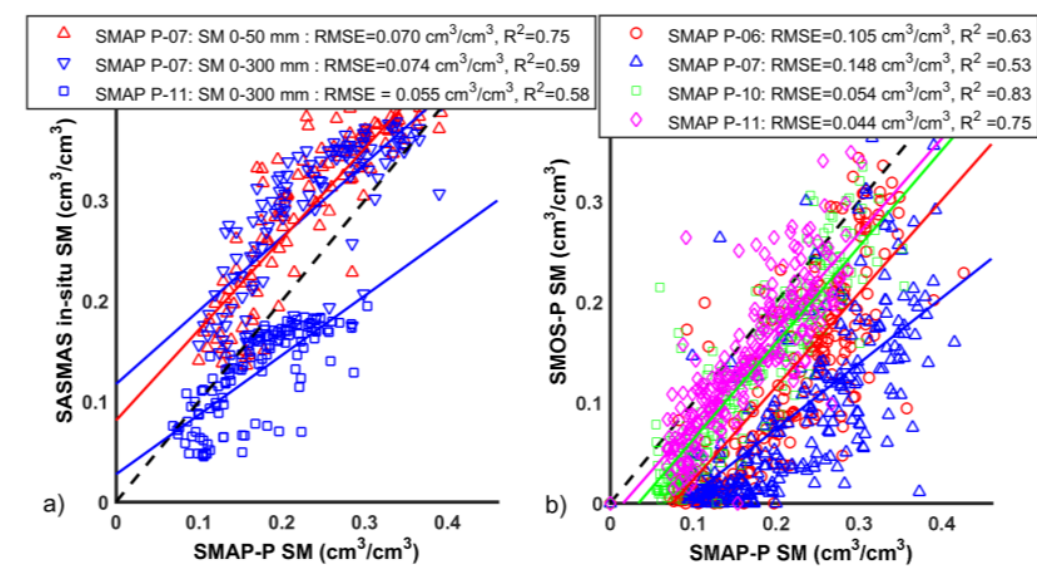

Figure 4. Comparison between (a) SMAP $36 \mathrm{~km}$ and SASMAS in-situ dataset, (b) SMAP-36 km and SMOS-25 km passive soil moisture products, over the Krui and Merriwa River catchments in 2015. 
Senanayake et al., Downscaling SMAP and SMOS soil moisture retrievals over the Goulburn River Catchment, Australia

$0.055 \mathrm{~cm}^{3} / \mathrm{cm}^{3}$ (Figure 4a). Comparing with SMAP, SMOS shows higher RMSE values with SASMAS insitu measurements at $0-30 \mathrm{~cm}$ soil profile, $0.15,0.18$ and $0.19 \mathrm{~cm}^{3} / \mathrm{cm}^{3}$, over three SMOS pixels.

Thereafter, a cross-comparison was carried out between SMAP and SMOS radiometric soil moisture products. Four SMAP $36 \mathrm{~km}$ pixels, P-06, P-07, P-10 and P-11, are distributed over the Krui and Merriwa River catchments (Figure 1). These four pixels are distributed over twelve SMOS $25 \mathrm{~km}$ pixels. The SMAP and SMOS soil moisture products were compared over the extent of these four SMAP pixels by using the weighted average of the SMOS data. The comparison between SMAP and SMOS passive soil moisture products across the SMAP pixels P-6, P-7, P-10 and P-11 showed RMSEs of $0.105,0.148,0.054,0.044 \mathrm{~cm}^{3} / \mathrm{cm}^{3}$ and $\mathrm{R}^{2}$ of $0.63,0.53,0.83,0.75$ respectively (Figure $4 \mathrm{~b}$ ). The combined dataset over the four SMAP pixels shows a

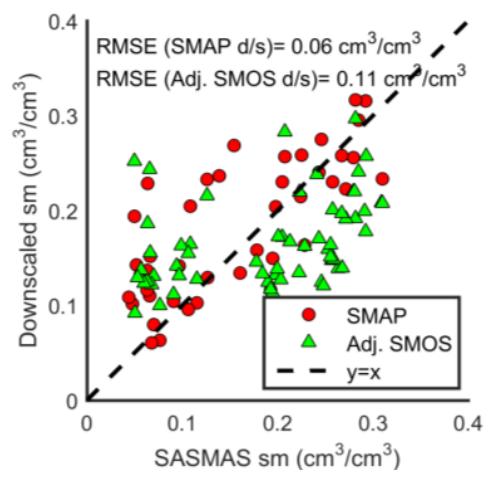

Figure 5. Comparison between SASMAS in-situ data with the downscaled SMAP and adjusted SMOS soil moisture data at S-3. RMSE of $0.098 \mathrm{~cm}^{3} / \mathrm{cm}^{3}$ between SMAP and SMOS data. This has been improved up to $0.059 \mathrm{~cm}^{3} / \mathrm{cm}^{3}$ after calibrating SMOS soil moisture retrievals using SMAP data.

\subsection{Validation of downscaled soil moisture products}

The in-situ data of SASMAS stations K-3, M-2, M-6, S-1 and S-3 were used in validating the downscaled soil moisture datasets. The SASMAS in-situ measurements show average RMSEs of $0.10(\sigma=$ $0.05), 0.19(\sigma=0.07)$ and $0.13(\sigma=0.02) \mathrm{cm}^{3} / \mathrm{cm}^{3}$ with the downscaled SMAP, SMOS and adjusted SMOS datasets respectively. The $1 \mathrm{~km}$ soil moisture data estimated from the $\Delta T-\theta \mu$ regressions show a RMSE of $0.13(\sigma=0.09) \mathrm{cm}^{3} / \mathrm{cm}^{3}$ with the in-situ measurements. Figure 5 demonstrates the comparison between downscaled SMAP data and downscaled Adjusted SMOS datasets with SASMAS in-situ measurements at the S-3 monitoring station.

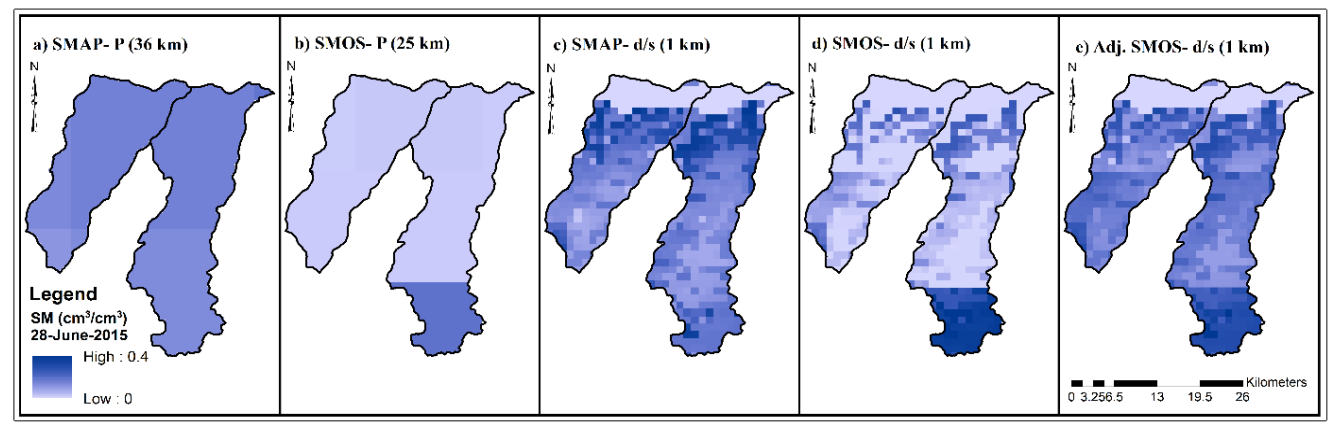

Figure 6. Spatial variability of soil moisture capture by (a) SMAP $36 \mathrm{~km}$ passive, (b) SMOS $25 \mathrm{~km}$ passive, (c) downscaled SMAP (1 km), (d) downscaled SMOS (1 km) and (e) downscaled adjusted SMOS $(1 \mathrm{~km})$ data over the Krui and Merriwa River catchments on $28^{\text {th }}$ June 2015.

\section{DISCUSSION AND CONCLUSIONS}

A number of algorithms have been used to downscale different satellite soil moisture products over the past couple of decades. Some recently tested SMAP downscaling methods include Bayesian Merging Method (Wu et al., 2017b), methods based on vegetation index and surface temperature (Knipper et al., 2016; Lakshmi and Li, 2016) and a near-infrared (NIR) - Red spectra based method (Chen et al., 2016). Wu et al. (2017a) has compared three active-passive downscaling algorithms, namely baseline algorithm, optional downscaling algorithm and a change detection method, to downscale SMAP soil moisture data into $9 \mathrm{~km}$ resolution.

SMOS soil moisture products show an underestimation of soil moisture with respect to both SMAP retrievals and SASMAS in-situ measurements. This observation is in agreement with several studies showing a general underestimation of SMOS soil moisture retrievals (Niclòs et al., 2016).

The downscaled SMAP soil moisture shows a better overall accuracy when compared to the downscaled SMOS soil moisture and adjusted SMOS soil moisture over the validation sites. Therefore, it is evident that the accuracy of the downscaled soil moisture products is highly dependent on the accuracy of the coarse-resolution 
Senanayake et al., Downscaling SMAP and SMOS soil moisture retrievals over the Goulburn River Catchment, Australia

satellite soil moisture products employed in the downscaling process. The downscaled adjusted SMOS dataset shows a better agreement with in-situ data compared to the downscaled non-adjusted SMOS dataset. Thus, a validation and comparison of SMAP and SMOS coarse-scale satellite products over a larger extent are required prior to expanding the downscaling method into a larger area.

The unavailability of densely distributed in-situ soil moisture observations at 0-5 cm soil depth in 2015 across the study area was a limitation to evaluate the spatial heterogeneity captured by the downscaled soil moisture datasets. The error of the downscaled data is slightly higher than the coarse-resolution soil moisture products when compared with the available in-situ measurements. The unavailability of evenly distributed multiple monitoring stations within $1 \mathrm{~km}$ pixels and the increased noise at finer resolution can be identified as the major reasons for this.

The spatial variability has been capture by the downscaled data in more detail compared to the coarse-resolution satellite soil moisture products (Figure 6). Although the underestimation of SMOS downscaled product is evident, Figure 6 shows that the spatial pattern of soil moisture is consistent between the downscaled SMAP and SMOS datasets over the study area. The validation work will be further extended into other soil moisture monitoring fields in the south-eastern Australia in the future by employing improved regression algorithms.

\section{REFERENCES}

Chen, N., He, Y., and Zhang, X. (2017). NIR-red spectra-based disaggregation of SMAP soil moisture to 250 $\mathrm{m}$ resolution based on smapex-4/5 in southeastern Australia. Remote Sensing, 9(1), 51.

Niclòs, R., Rivas, R., García-Santos, V., Doña, C., Valor, E., Holzman, M., Bayala, M., Carmona, F., Ocampo, D., Soldano, Á., Thibeault, M., Caselles, V., and Sánches, M. (2016). SMOS level-2 soil moisture product evaluation in Rain-fed croplands of the Pampean Region of Argentina. IEEE Transactions on Geoscience and Remote Sensing, 54(1), pp.499-512. Fang, B., Lakshmi, V., Bindlish, R., Jackson, T. J., Cosh, M., \& Basara, J. (2013). Passive microwave soil moisture downscaling using vegetation index and skin surface temperature. Vadose Zone Journal, 12(3).

Fang, B., and Lakshmi, V. (2014). Soil moisture at watershed scale: Remote sensing techniques. Journal of hydrology, 516, 258-272.

Knipper, K. R., Hogue, T. S., Franz, K. J., and Scott, R. L. (2017). Downscaling SMAP and SMOS soil moisture with moderate-resolution imaging spectroradiometer visible and infrared products over southern Arizona. Journal of Applied Remote Sensing, 11(2), 026021-026021.

Lakshmi, V., and Li, H. (2016). Spatial downscaling of SMAP passive microwave radiometer soil moisture using vegetation index and surface temperature. Geoscience and Remote Sensing Symposium (IGARSS), Beijing, 2016.

Price, J. C. (1977). Thermal inertia mapping: A new view of the earth. Journal of Geophysical Research, 82(18), 2582-2590.

Rüdiger, C., Hancock, G., Hemakumara, H.M., Jacobs, B., Kalma, J.D., Martinez, C., Thyer, M., Walker, J.P., Wells, T. and Willgoose, G.R. (2007). Goulburn River experimental catchment data set. Water Resources Research, 43(10), W10403.

Senanayake, I.P., Yeo, I.Y., Tangdamrongsub, N., Willgoose, G.R., Hancock, G.R., and Wells, T. (2017). Disaggregation of SMAP radiometric soil moisture measurements at catchment scale using MODIS land surface temperature data. Proceedings of the $4^{\text {th }}$ annual conference of Research @ Locate, Sydney, 2017.

Western, A. W., Grayson, R. B., and Blöschl, G. (2002). Scaling of soil moisture: A hydrologic perspective. Annual Review of Earth and Planetary Sciences, 30(1), 149-180.

Wu, X., Walker, J. P., Rüdiger, C., Panciera, R., and Gao, Y. (2017a). Intercomparison of Alternate Soil Moisture Downscaling Algorithms Using Active-Passive Microwave Observations. IEEE Geoscience and Remote Sensing Letters, 14(2), 179-183.

Wu, X., Walker, J. P., Rüdiger, C., Panciera, R., and Gao, Y. (2017b). Medium-Resolution Soil Moisture Retrieval Using the Bayesian Merging Method. IEEE Transactions on Geoscience and Remote Sensing (accepted article). 